\title{
Phytoremediation of ionic and methylmercury pollution
}

Principal Investigator: Richard B. Meagher, Professor, Department of Genetics, Life Sciences Building, Green Street, University of Georgia, Athens, GA 30602, phone: 706542-1444, fax: 706-542-1387, email: Meagher@uga.edu,

web: http://www.genetics.uga.edu/rbmlab/

\section{FINAL REPORT 2010}

Our long-term goal is to enable highly productive plant species to extract, resist, detoxify, and sequester the toxic elemental pollutants, like the heavy metal mercury. Mercury pollution, primarily due to methylmercury $\left(\mathrm{MeHg}, \mathrm{CH}_{3} \mathrm{Hg}^{+}\right)$produced by native bacteria at mercury contaminated wetland sites, is a world-wide problem seriously affecting the health of human and wildlife populations. $\mathrm{MeHg}$ is inherently more toxic than metallic $\mathrm{Hg}(\mathrm{O})$ or ionic $\mathrm{Hg}(\mathrm{II})$ mercury, and because $\mathrm{MeHg}$ is efficiently biomagnified up the food chain, it poses the most immediate threat to animal populations. Our current working hypothesis is that transgenic plants controlling the transport, chemical speciation, electrochemical state, volatilization, and aboveground binding of mercury will: a) tolerate mercury and grow rapidly in mercury contaminated environments; b) prevent methylmercury from entering the food chain; c) remove mercury from polluted soil and water; and d) hyperaccumulate mercury in aboveground tissues for later harvest (Meagher et al.. 2006; Meagher, 2007).

Our previous research has significantly increased mercury tolerance and detoxification in plants beyond what might be needed at most field sites and increased in situ processing rates of different mercury species. However, the levels and rates of mercury transport, aboveground volatilization, and/or hyperaccumulation are still not high enough to provide for a rapid cleanup of contaminated sites. Recentiy we have shifted our goal from engineering plants that can volatilize $0.1 \%$ of their dry weight (dw) per year of mercury plants than can hyperaccumulate $1000 \mathrm{ppm} \mathrm{dw}$ in mercury aboveground in one year.

RESEARCH PROJECT RESULTS AND IMPLICATIONS: The following report describes our progress over the last year.

Specific Aim 1: To increase the transport of mercury into roots and to aboveground vegetative organs. Zinc transporters: Mercury $(\mathrm{Hg})$ is a chemical analog of zinc $(\mathrm{Zn})$, is in the same element group in the periodic table, and they share many physical properties. To uptake $\mathrm{Zn}$ across their root plasma membranes (PM) from the environment and transport it from cell to cell in the apoplast plants use high affinity $\mathrm{Zn}$ transporters (ZIPs). We hypothesized that mercury is take up by this system and want to enhance this route of uptake.

We have examined the Arabidopsis ZIPs transporters (ZIP) for their ability to transport mercury and identified several that worked in yeast. Surprisingly, transgenic plant lines strongly expressing two of the three ZIP transporters examined were significantly more resistant to 65 uM mercury in their media than wild-type and accumulated much less mercury. Thus, this gene confers the opposite phenotype to plants from what it conferred to yeast.

To explore one extreme explanation of this phenotype we examined the epigenetic control over ZIP gene expression. We made an interesting discovery that many of the high affinity zinc and phosphate transporter genes are derepressed in actin-related protein6 (ARP6) and ARP5 mutants defective in chromatin remodeling and epigenetic control (Smith et al., In prep; Smith et al., Submitted). There also appears to be control 
over the post-transcriptional processing of ZIPs that produces mercury resistance phenotype.

In addition we collaborated on the construction of a transgenic cottonwood that could process methylmercury two steps to metallic mercury (Lyyra et al., 2007).

Specific Aim 2: To increase biochemical sinks and storage for mercury in leaves. Manipulation of the phytochelatin (PC) biosynthesis pathway has produced our most significant increases in mercury accumulation. We characterized three genes encoding the essential enzymes in the PC pathway (ECS, GS, PCS). Strong constitutive expression of any one of these enzymes in shoots and roots conferred low levels of mercury resistance to plants and small approximately $30 \%$ increases mercury accumulation ( $\mathrm{Li}$ et al., 2004; Li et al., 2005; Li et al., 2006b). ECS is the first and committed step in this pathway and produced the strongest results, but expressing ECS alone the shoot-specific expression also did not result in an increase in aboveground mercury over constitutive ECS expression, only increasing total transport rates ( $\mathrm{Li}$ et al., 2006a). However, when we expressed the first two enzymes in this pathway together, ECS and GS, we obtained a striking improvement in mercury metabolism ( $\mathrm{Li}$ et al., $2006 \mathrm{~b}$ ). These plants were 35 -fold more resistant to mercury than WT (i.e., accumulated 35-fold more fresh weight on $65 \mathrm{mM}$ mercury) and accumulated 3-fold more mercury aboveground. Thus, we had achieved a 100 -fold improvement in mercury processing by these plants. It appears the glutathione conjugates of mercury $(\mathrm{Hg}(\mathrm{II}))$ are less toxic and may be transported into the vacuole.

Specific Aim 3: To increase leaf cell vacuolar storage of mercury. The practical goal of this specific aim, was to achieve high levels of mercury storage in plant vacuoles in aboveground tissues. Using a genomics approach have demonstrated that only 4 of the 14 predicted Arabidopsis glutathione conjugate pumps are induced by mercury. We have begun to clone these four very large genes for plant expression.

Last year we cloned the yeast glutathione conjugate pump, YCF1 under control of a plant constitutive promoter and tested its phenotype in transgenic plants. Previous efforts have shown that this yeast gene increased lead and cadmium accumulation in plants. We found that YCF1 expression did in fact increase mercury resistance to Arabidopsis. We expect this will be as a result of increased vacuolar storage and increased accumulation. We have recently recloned YCF1 for leaf specific expression using a ribulose bisphosphate carboxylase small subunit promoter constructed as part of this grant (Dhankher et al., 2002).

However, we found the YCF1 gene was poorly expressed, 20-fold lower levels than most genes expressed from the constitutive actin vector we used. After some effort we determined that the poor expression appears to be due to a cryptic polyadenylation site (PA) $500 \mathrm{nt}$ into what should be a large $4500 \mathrm{nt}$ transcript. We have just completed a site directed mutagenesis of YCF1, fixing in separate and combined constructs two PA sites and amending the gene with plant tonoplast localization sites. These constructs were transformed into Arabidopsis and assayed for improved mercury processing and storage. A manuscript is in preparation (LeBlanc \& Meagher, in prep.).

Specific Aim 4: To demonstrate that several stacked transgenes, when functioning in concert, enhance mercury resistance and hyperaccumulation to high levels. We have identified four major genes for mercury processing that may be combined into one plant (Meagher et al., 2006; Meagher, 2007a, b). In the process of working on this strategy we discovered genes that affected phosphate uptake and processing (Smith et al., 2010, Jain et al., 2009). 


\title{
INFORMATION ACCESS (PUBLICATIONS AND WEB SITE)
}

\author{
http://www.genetics.uga.edu/rbmlab/
}

Dhankher, O.P.s Li, Y., Rosen, B.P., Shi, J., Salt, D., Senecoff, J.F., Sashti, N.A., and Meagher, R.B. (2002). Engineering tolerance and hyperaccumulation of arsenic in plants by combining arsenate reductase and gamma-glutamylcysteine synthetase expression. Nat Biotechnol 20, 1140-5.

http://www.ncbi.nlm.nih.gov/entrez/query.fcgi?cmd=Retrieve\&db=PubMed\&dopt=Citation\&list uids $=12368812$

Li, Y., Dankher, O.P., Carreira, L., Smith, A.P., and Meagher, R.B. (2006a). The shootspecific expression of gamma-glutamylcysteine synthetase directs the long-distance transport of thiol-peptides to roots conferring tolerance to mercury and arsenic. Plant Physiol 141, 28898.

http://www.ncbi.nlm.nih.gov/entrez/query.fcgi?cmd=Retrieve\&db=PubMed\&dopt=Citation\&list_ uids $=16581878$

Li, Y., Dhankher, O., Carreira, L., Balish, R., and Meagher, R. (2005). Arsenic and mercury tolerance and cadmium sensitivity in plants expression of bacterial gamma-glutamylcysteine synthetase. Env Tox \& Chem 24, 1376-1386.

http://www.setacjournals.org/perlserv/?request=get-pdf\&doi=10.1897\%2F04-340R.1

LI, Y., Dhankher, O.P., Carreira, L., Lee, D., Chen, A., Schroeder, J.l., Balish, R.S., and Meagher, R.B. (2004). Overexpression of phytochelatin synthase in Arabidopsis leads to enhanced arsenic tolerance and cadmium hypersensitivity. Plant Cell Physiol 45, 1787-97. http://www.ncbi.nlm.nih.gov/entrez/query.fcgi?cmd=Retrieve\&db=PubMed\&dopt=Citation\&list uids=15653797

LI, Y., Heaton, A.C.P., Carreira, L., and Meagher, R.B. (2006b). Enhanced tolerance to and accumulation of mercury, but not arsenic, in plants overexpressing two enzymes required for thiol peptide synthesis. Physiologia Plantarum 128, 48-57.

http://search.ebscohost.com/login. aspx?direct=true\&db=a9h\&AN=21909710\&site=ehost-live

Meagher, R.B. (2007). Multigene strategies for engineering the phytoremediation of mercury and arsenic. In: Biotechnology and Sustainable Agriculture 2006 and Beyond: Proceeding of the 11th IAPTC\&B Congress, Z. Xu, J. Li, Y. Xue, and W. Yang, eds (Beijing, China: Springer), 49-60.

Jain, A., Poling, M.D., Smith, A.P., Nagarajan, V.K., Lahner, B., Meagher, R.B., and Raghothama, K.G. (2009). Variations in the composition of gelling agents affect morphophysiological and molecular responses to deficiencies of phosphate and other nutrients. Plant Physiol 150, 1033-49.

hitp://www. ncbi.nlm. nih. qov/entrez/query fcai?cmd=Retrieve\&db=PubMed\&dopt=Citatio n\&list uids $=19386810$

Lyyra, S., Meagher, R.B., Kim, T., Heaton, A., Montello, P., Balish, R.S., and Merkle, S.A. (2007). Coupling two mercury resistance genes in Eastern cottonwood enhances the processing of organomercury. Plant Biotechnol J 5, 254-62.

http://www.ncbi.nlm.nih. gov/entrez/query.fcgi? $\mathrm{cmd}=$ Retrieve\&d $\mathrm{b}=$ PubMed\&dopt=Citatio n\&list uids $=17309680$ 
Meagher, R.B., Kim, T., Smith, A.P., and Heaton, A.C.P. (2007). Designing plants for the remediation mercury- and arsenic-polluted soils and water. In: Designing Industrial Crops, T. McKeon, and L. Jiann-Tsyh, eds American Chemical Society Books), pp. 272.

Smith, A.P., Jain, A., Deal, R.B., Nagarajan, V.K., Poling, M.D., Raghothama, K.G., and Meagher, R.B. (2010). Histone H2A.Z regulates the expression of several classes of phosphate starvation response genes but not as a transcriptional activator. Plant Physiol 152, 217-25.

http:/www.ncbi.nlm.nih.gov/entrez/query fcgi?cmd=Retrieve\&db=PubMed\&dopt=Citatio n\&list uids $=19897606$. 